\title{
TRADUCCIÓN INTERSEMIÓTICA: TEORÍAS Y PROPUESTAS PARA SU ESTUDIO EN LA LITERATURA Y EL CINE ${ }^{1}$
}

\author{
INTERSEMIOTIC TRANSLATION. THEORIES AND APPROACHES \\ FOR ITS STUDY IN LITERATURE AND CINEMA
}

\author{
María del Sol MORALES ZEA \\ Universidad de Guanajuato (México) \\ maria.zea.85@gmail.com
}

\begin{abstract}
Resumen: El presente texto es una revisión de la noción de traducción intersemiótica desde su creación por parte de Jakobson en 1959, y a través de su recuperación en el ámbito de la semiótica, el análisis literario y cinematográfico. La primera parte surge de la necesidad de tener claridad sobre las bases teóricas que delinean los alcances y limitaciones de la intersemiosis, sus derivaciones y propuestas alternas, con especial atención de los postulados de Eco, Lotman, y Sonesson. La segunda parte aborda la aplicación de la teoría al estudio de las obras de traducción intersemiótica, enunciando los modelos de análisis propuestos a partir de la glosemática, el cronotopo, la idea de semiosfera, y el Análisis Multimodal del Discurso.
\end{abstract}

Palabras clave: Traducción. Intersemiosis. Transposición. Narratología. Transmutación.

\begin{abstract}
This article reviews the notion of intersemiotic translation since it was stablished by Jakobson in 1959, and uses it in the field of semiotic, literary, and cinematographic analysis. First, the article will approach and clarify the theoretical aspects of the concept, together with its scope, limitations, and derivations, and will address alternative proposals, paying special attention to Eco, Lotman, and Sonesson. Secondly, the article will apply the theory to the study of intersemiotic translation, outlining the analysis models that derives from glossematics, the chronotope, the idea of semiosphere, and Multimodal Analysis of Discourse.
\end{abstract}

Keywords: Translation. Intersemiosis. Transposition. Narratology. Transmutation.

\footnotetext{
${ }^{1}$ Este trabajo fue realizado durante el segundo año de estancia posdoctoral en la Maestría en Literatura Hispanoamérica de la Universidad de Guanajuato (México), gracias al programa de Becas ConacytEstancias Posdoctorales Vinculadas al Fortalecimiento de la Calidad del Posgrado Nacional 2020 (2).
}

(C) UNED. Revista Signa 31 (2022), pp. 595-609

DOI: https://10.5944/signa.vol31.2022.29409

ISSN digital: 2254-9307. ISSN papel: 1133-3634 


\section{INTRODUCCIÓN}

La incesante demanda por contenidos innovadores que vayan a la par de las nuevas tecnologías, la constante disputa por los públicos con la promesa de grandes ganancias, y la preocupación de los especialistas por llevar contenidos a las nuevas generaciones, han propiciado más que nunca la repetición de títulos, argumentos, historias y motivos en distintos sistemas semióticos. El traslado de una obra de un lenguaje a otro no es algo único de las últimas décadas, podemos hablar de la forma en que los artistas medievales retomaron temas de la Biblia, o de cómo el Renacimiento se apropió del arte griego y romano. Con todo, es hasta el siglo XX que tales procesos se convirtieron en objeto de análisis para los especialistas de las diferentes disciplinas involucradas. Los estudiosos del cine y la literatura han sido los más entusiastas observadores de este fenómeno - que se conoce generalmente como adaptación-. Se registran obras que van de la literatura al cine, del cine a la literatura, del teatro al cine, del cine al teatro, de la música al cine, del cine a la música, y en menor medida de la pintura al cine y a la inversa. Esta diversidad de formas y medidas ha llevado a cuestionar la base teórica y epistemológica desde la que las estudiamos.

Frente al problema del estudio de la transposición, la semiótica, y específicamente las teorías de la traducción y la narratología, han proporcionado una base sólida para el análisis cimentada en los trabajos de la escuela de Praga y la escuela de Copenhague, así como por la escuela de Tartu-Moscú y los semiólogos italianos. En correspondencia con tal afirmación, el objetivo de este trabajo es hacer una revisión de la categoría de traducción intersemiótica promovida por Jakobson en 1959, a través de sus críticas y reinterpretaciones. Asimismo, se recuperarán las propuestas metodológicas actuales en el estudio comparativo del cine y la literatura, para finalmente hacer un balance de los corolarios y problemas que enfrenta la traducción intersemiótica como postulado teórico.

\section{PRIMERA ETAPA: LOS ORÍGENES DE LA TRADUCCIÓN, TRANSPOSICIÓN Y TRASMUTACIÓN INTERSEMIÓTICA}

Iniciaremos por señalar a los tres referentes fundamentales en la teoría de la traducción intersemiótica: Roman Jakobson, Louis Hjelmslev y Algirdas Greimas. Fue Jakobson, miembro de la escuela de Praga, el creador del concepto que aparece en su texto "On Linguistics Aspects on Translation" (1959). En dicho trabajo abordó la traducción como una operación no de sustitución de un signo por otro, sino como la búsqueda de la esencia del signo que se quiere traducir, es decir su interpretación, idea que reconoce proviene de Charles S. Peirce. Para Jakobson, el punto nodal estaba puesto en quien interpreta y realiza la operación de trasvase de acuerdo con su propio criterio, es decir, en términos de Peirce, quien crea el signo interpretante del primer signo en su 
mente ${ }^{2}$. El intérprete es quien lleva el contenido de un sistema semiótico a otro, no signo a signo, sino signo a significado. A partir de esto, identifica tres maneras de interpretar un signo lingüístico: la traducción intralingüística (o reformulación dentro de una misma lengua), la traducción interlingüística (o la traducción propiamente dicha) y la traducción intersemiótica (o transmutación), la cual define como "una interpretación de signos verbales por significados de un sistema de signos no verbales" (1959: 233). Vale la pena detenernos en el sinónimo transmutación, que enfatiza la idea de cambio (mutación) que es inseparable de este fenómeno y que será subrayado también en estudios posteriores.

Previamente, en 1943, y generando una línea teórica paralela desde la escuela de Copenhague, Louis Hjelmslev había formulado su teoría de la glosemática, en la que consideraba a la semiótica como la ciencia adecuada para el análisis de los signos y de los diferentes sistemas que los componen. Argumentaba que: "En la práctica, una lengua es la semiótica a la que pueden traducirse todas las demás semióticas - tanto las demás lenguas como las demás estructuras semióticas concebibles_-” (1971: 153). La productividad de un texto no tiene restricciones, afirmó Hjelmslev, por lo que siempre habría "traducibilidad", es decir "sustitución de la expresión [...] cualquier derivado textual (por ejemplo, un capítulo) puede traducirse de una forma estilística, estilo, estilo axiológico, medio, tono, lengua vulgar, lengua nacional, lengua regional o fisonomía a otro" (1971: 164). Pese a esto, él aún advertía problemas al salir del esquema de la lengua: "esta traducibilidad no siempre es recíproca cuando se trata de alguna otra semiótica distinta de la lengua" (1971: 164).

Para el análisis, en sus Prolegómenos a una teoría del lenguaje, Hjelmslev designó a los elementos del signo como contenido y expresión (en lugar de significante y significado), el análisis de estos elementos se haría sobre la forma y sustancia de cada uno. A pesar de que él construye su teoría y pone ejemplos de las lenguas naturales por tratarse de su área de conocimiento, pensaba que ésta tendría "aplicabilidad universal a sistemas de signos (o a sistemas de figuras con fines sígnicos)" (1971: 145), dejando a los especialistas de cada área la tarea de extrapolar su modelo. En ese sentido, aunque Hjelmslev no aborda el fenómeno de la traducción entre sistemas, sí establece bases teóricas para realizar análisis comparativos.

Por su parte, Algirdas Greimas, en su Semántica estructural, analizó el tema de las posibilidades de las lenguas naturales, las cuales podrían transponerse a un "orden sensorial diferente" (1987: 18). En su estudio, Greimas admitió que las trasposiciones adquirirían autonomía total o relativa en la medida en que se configuraran como otro lenguaje, lo que sería de especial interés para la semiótica. En todo caso, las diferencias entre el significante inicial y la traducción son, para el autor, muestra de la alienación y valorización hecha por el traductor (1987: 19-20). También reconoce el valor de la teoría

\footnotetext{
${ }^{2}$ En su teoría del signo, Peirce refiere que el signo o representamen es algo que representa algún aspecto de algo, y, al estar dirigido a alguien (intérprete) crea en su mente un signo equivalente que es el interpretante del primer signo (o representamen). El aspecto de ese algo, sobre el que se establece la relación es el fundamento del representamen (Peirce, 1974: 22).
} 
semiótica de Hjelmslev a la que considera la primera "coherente y acabada" (Greimas y Courtés, 1982: 200), así como su concepción del lenguaje como un sistema semiótico más, sobre el que también había argumentado Émile Benveniste ${ }^{3}$.

En trabajos posteriores, Jakobson fue crítico de la aplicación del concepto de signo y lenguaje postulados por Saussure a sistemas no lingüísticos, pues consideraba que el lenguaje se encontraba en el círculo central de la semiótica, un sistema puramente semiótico. Es decir, tenía una postura contraria a la de Hjelmslev y Greimas respecto a sistemas semióticos no lingüísticos tales como el arte cinematográfico (Jakobson, 1988). Es de resaltar que la prolongada obra del autor le permitió ser testigo de la evolución del lenguaje cinematográfico, desde hitos como la aparición del cine sonoro hasta la consolidación de su técnica. Sobre esto, al analizar otros sistemas de comunicación, resaltó la diferencia entre los mensajes homogéneos, creados en un sistema semiótico, y los mensajes sincréticos, resultado de la combinación de sistemas semióticos (Jakobson, 1988: 308), tales como el cine.

En su etapa tardía, Jakobson asume que la transmutación es una "transformación compleja que opera en el pasaje de un sistema de signos a otro: de un medio a otro, de una tecnología a otra, en una situación en la que difieren los contextos, así como los lugares de recepción" (Jakobson citado por Vinelli). Jakobson coincide con Greimas en que es en el lenguaje artístico donde se pueden establecer correlatos entre las artes, las cuales divide en: temporales (música y poesía), espaciales (pintura y escultura), y espacio temporales o sincréticas (teatro, cine, performance). Finalmente, observa que la retórica fílmica se construye a través de los tropos fílmicos o planos y el montaje, que constituyen su narrativa (Jakobson, 1988) ${ }^{4}$.

Las ideas de Jakobson, Hjelmslev y Greimas son la base para toda la teoría posterior, que recuperará en diferentes momentos sus conceptos y posturas sobre la traducción intersemiótica, como podremos ver más adelante. Sin embargo, la circulación entre sistemas semióticos no interesó únicamente a los semiólogos, sino también y muy marcadamente a los estudiosos de la literatura y el cine - específicamente a través de la narratividad-. En esa línea, son famosos los estudios sobre narrativa con enfoque estructuralista de Seymour Chatman, el cual advierte que la posibilidad de trasponer una historia de un medio a otro es lo que hace evidente que las estructuras narrativas son independientes de sus medios (1978: 19-21). Por tanto, sería posible trasladar una historia de un medio a otro conservando en mayor o menor medida su argumento de acuerdo con las posibilidades del medio, es decir, adaptándolo.

\footnotetext{
${ }^{3}$ Benveniste recrea la postura de Peirce, en la cual los signos no son dominados por la lengua, mientras critica la preeminencia que atribuye Saussure a la lengua, diferencia que lleva a la distinción entre semiótica y semiología (1999: 48-52).

${ }^{4}$ A pesar del gran interés de Jakobson en el cine, que lo llevó a expresar algunas ideas sobre él, no pudo escribir más que un texto específico sobre el tema: “Decadencia en el cine?”, en donde defiende al cine sonoro de las críticas, alegando que el sonido debía abonar a la sinécdoque cinematográfica (Jakobson, 1976; Puyal, 2011).
} 
En la teoría literaria, la noción de la intertextualidad inicialmente formulada por Julia Kristeva en respuesta al dialogismo de Mijail Bajtin, puede incluir a la transposición. Kristeva afirma que la intertextualidad es permanente en la cultura, todo texto conlleva citas y referencias a otros textos, pues "todo texto es absorción o transformación de otro" (1997:3). De acuerdo con esta idea, Gerard Genette al formular su teoría de la transtextualidad, a partir de la teoría de Kristeva, define la hipertextualidad como el paso de un texto $\mathrm{A}$ a un texto B por un proceso de transformación. De esta forma, consideró a la transposición como un tipo de transformación especial dentro de su teoría, debido a su importancia y a la diversidad de procedimientos posibles (1989a: 262). En consecuencia, Genette incluyó en sus análisis narratológicos obras cinematográficas, a las que consideró una expresión más de la narración, en las que es posible estudiar los mismos elementos de la narración literaria, considerando las diferencias del medio (Genette, 1989b).

Roland Barthes, retomó a su vez la teoría de la intertextualidad de Kristeva (2004), y pese a no realizar análisis específicos de traducción o transposición, sí se ocupó de una teoría que no se limita a un lenguaje o medio: el mito como "sistema semiológico segundo" (2011). Con esto subrayó la importancia de la narración al interior de las diferentes expresiones artísticas. De la misma forma, Umberto Eco se ocupó del proceso de mitificación al que definió en el primer párrafo de su ensayo "El mito de supermán":

como simbolización inconsciente, como identificación del objeto con una suma de finalidades no siempre racionalizables, como proyección en la imagen de tendencias, aspiraciones y temores emergidos particularmente, en un individuo, en una comunidad, en todo un periodo histórico (Eco, 1984: 249).

El mito no se expresa ni se construye únicamente a través de un sistema semiótico, sino que puede tener diversos medios y lenguajes. En este caso, igual que al hablar de la traducción, Eco confiere centralidad al contexto en el cual se crea y se inserta tanto el mito como la obra de llegada, así como al intérprete del signo.

En el ámbito de los estudios sobre cine, Christian Metz estableció los elementos del lenguaje cinematográfico, a través de un agudo repaso de las teorías de Saussure, Greimas y Hjelmslev; y al hacerlo lo acreditó como propicio para el análisis semiótico. En su caracterización, Metz concluye que el cine es un lenguaje que conjunta otros y al mismo tiempo también puede manejar varios códigos, así, se refiere a, "los préstamos, calcos, imitaciones, adaptaciones de figuras significantes" de otros lenguajes, como "interferencias semiológicas entre las artes" (1973: 258), que a su vez permiten la comunicación entre ellas. Al tercer tipo de interferencias semiológicas los llamará "grupo de transposiciones códicas" (Metz, 1973: 262), este sería el caso en que un código es llevado a otro lenguaje que requiere una transposición sensorial, y por tanto un cambio en el código, esto es, cuando ocurre una mayor transformación o mutación. Al igual que Barthes y otros estructuralistas, en sus estudios aplicó las teorías de la narratología al análisis de filmes específicos (Metz, 1970; 2002), buscando la inclusión de las características del lenguaje cinematográfico. En las décadas siguientes, con la 
consolidación del arte cinematográfico y el aumento de estudios especializados en la adaptación, se profundizará en la identificación de áreas de oportunidad y límites de la traducción intersemiótica en el cine.

\section{SEGUNDA ETAPA: LA TEORÍA DE LA TRADUCCIÓN}

A fines del siglo XX, los semiólogos italianos retomaron el estudio de la traducción en su base teórica. Entre 1997 y 1999, en el marco de dos seminarios del doctorado en semiótica de la Universidad de Bologna (Eco, 2008: 16) ${ }^{5}$, Eco y Paolo Fabbri entre otros ${ }^{6}$, discutieron sobre la traducción intersemiótica de Jakobson, acontecimiento que Elena Vinelli llama el Debate de Bologna (2009). A partir de esto, las preguntas y propuestas sobre la transposición y la traducción interlingüística e intersemiótica toman impulso como una línea de investigación necesaria y constante, que involucra a la semiótica, la lingüística, el análisis literario, y los estudios sobre las diferentes artes. Al frente de los problemas teóricos y conceptuales se encuentra la habitual jerarquización de las obras que lleva a buscar la fidelidad, equivalencia o, en su defecto, adecuación en las obras posteriores.

En el Debate se atrajeron elementos que continúan siendo relevantes para el estudio del fenómeno intersemiótico: la recuperación de las teorías de Greimas; la atención sobre el caso de la traducción al cine estudiada a profundidad por Christian Metz; el aporte de la semiótica cultural y la relación entre la obra, su público y el lugar así como la importancia de los géneros; y finalmente, la revaloración de la adaptación de los textos a los códigos culturales de llegada antes que el interés en la fidelidad (Vinelli, 2009). Aunque todos estos temas continúan siendo ejes para los estudios de traducción intersemiótica, la traducción como problema teórico ha derivado en nuevas interrogantes.

El mismo Eco, en obras posteriores, cuestionó la homologación entre traducción e interpretación que se encuentra tanto en la teoría de Peirce como en la de Jakobson (2008: 295-295), por ello analizó el proceso de interpretación para intentar conocer sus mecanismos, los cuales sintetiza en la idea de negociación. Así, en la negociación de Eco intervienen el texto fuente, el autor y la cultura donde se crea, pero también el texto de llegada, la cultura receptora e incluso la industria editorial (Eco, 2008: 25). Igualmente, incluyó una nueva forma de traducción, la traducción intrasistémica, la que ocurre dentro del mismo sistema no lingüístico (Eco, 2008). Es el tipo de traducción que ocurre en los remakes cinematográficos, o el paso de serie televisiva a película, que son cada vez más frecuentes debido a la multiplicación de los medios propiciada por la internet.

\footnotetext{
${ }^{5}$ Los argumentos de este debate se publicaron en la revista $V S$, número 82 (1999) y VS números 85-87 (2000) (Eco, 2008: 16).

${ }^{6}$ Otros participantes fueron: Morana Alac, Daniele Barbieri, Patrick Cattrysse, Gian Paolo Caprettini, Mauricio Gagliano, Ugo Volli, Alfredo Tenoch Cid, Gianfranco Marrone, Omar Calabrese, Siri Nergaard, Giovanna Fanci, Francis Vanoye, Paolo Vinçon, Anne Freadman, André Helbo y Nicola Dusi (Vinelli, 2009).
} 
Otro participante del Debate, Omar Calabrese hace una acotación a la teoría de Jakobson, al afirmar que "no todos los sistemas semióticos son equivalentes" (Calabrese, 2000: 103), pues hay sistemas (la música) que son a la vez parte de sistemas de sistemas (el cine). Algo que recuerda la división de Jakobson entre mensajes homogéneos y sincréticos. La reflexión de Calabrese, no obstante, agrega que mientras esto varíe de caso a caso, no se puede establecer una teoría general, sino solo teorías específicas para casos individuales. Y que, en última instancia, la traducción es una transferencia de significados que implica la transformación, cuyo enfoque es decidido por el agente operador (Calabrese, 2000) o intérprete.

En fechas más recientes frente a los debates por la denominación, Nicola Dusi — también participante del Debate-, ha propuesto "que todos los casos de traducción intersemiótica, transmutación o adaptación, podrían ser agrupados juntos en la esfera de la transposición, independientemente de si son audiovisuales, musicales, teatrales, performativos u otros" (Dusi, 2015: 202). Esto responde a la discusión fundamental sobre la pertinencia del término traducción que es criticado por un variado y nutrido grupo de especialistas, aunque no se ha logrado sustituir el término de Jakobson.

No obstante, la vigencia de los estudios sobre traducción intersemiótica en la sociedad actual alcanza su versión más ambiciosa en los trabajos de Peeter Torop, quien a su vez recupera las teorías de Iuri Lotman y la escuela de Tartu-Moscú ${ }^{7}$. Al explicar su noción de semiosfera o espacio semiótico, Lotman señala que existe en él un intercambio constante de información que al enfrentarse con el mundo externo genera "traducciones metafóricas", las cuales transforman los dos textos involucrados (Lotman, 1998: 107). En la comunicación, el mensaje requiere ser interpretado y por tanto traducido mediante el diálogo entre el "microcosmos interior del hombre y el macrocosmos del universo que lo rodea" (Lotman, 1998: 134). A partir de esto, la teoría de Lotman confiere un lugar central a la traducción dentro de los procesos semióticos, y, de hecho, en todo acto de comunicación.

En continuidad con la teoría de Lotman, Torop ha realizado diversos análisis sobre la intersemiosis. Propone un "modelo taxonómico virtual del proceso de traducción" en el que hace patente la diversidad de traducciones posibles para un texto fuente, que hace inútil hablar de una traducción ideal o única (Torop, 2002). No obstante, lo más llamativo de su trabajo es la concepción de la cultura actual como un flujo constante de traducciones intersemióticas; y que, en suma "es posible describir a la cultura como un proceso infinito de traducción total" (2002: 2), esta tesis la desarrolló en su libro Totalny Perevod de 1995. La cultura, así vista, sería el conjunto de traducciones que manifiestan la autocomunicación dentro de la cultura, misma que permite la creación de nuevos códigos y significados (2002: 2). A esta constante intertextualidad se añade la diversidad de medios disponibles para la transmisión de los textos o intermedialidad; así como la interdiscursividad, o la combinación de diferentes convenciones del lenguaje como

\footnotetext{
${ }^{7}$ Sobre la influencia de dicha escuela en América latina véase Cáceres (2003).
} 
género, discurso o estilo (Torop, 2020), los cuales transforman en diferente medida su recepción e interpretación al fluir en el espacio intersemiótico (Torop, 2004).

Por su parte, Goran Sonesson reclama el estudio de la traducción como una materia propia de la semiótica cognoscitiva, al tiempo que ha criticado el uso del término traducción por considerar que representa una relación de cambio de lugar o "metáfora de tubo" (2018-2019), y prefiere referirse a transposición —al igual que Dusi-, término que permitiría pensar en un proceso de cambio de nivel (2019: 94). Para él, "el traductor es un sujeto doblemente activo, como intérprete y como creador de un nuevo texto [y el resultado] debe situarse en un punto dado entre la dimensión hermenéutica y la dimensión retórica de ambos actos de comunicación" (2018-2019: 180). Al adentrarse en las posibilidades de cada lenguaje, afirma que el lenguaje tiene límites en su capacidad de transmitir cualidades sensoriales. Sin embargo, reconoce que la imagen tiene una limitación igualmente importante, que es la imposibilidad de representar óptimamente la continuidad temporal o espacial, sino únicamente conjuntos limitados de sus cualidades. Por tanto, es imposible que el traductor pueda expresar todo el contenido del mensaje original en una traducción intersemiótica, por lo que, remarca, se debe hablar de una transposición intersemiótica (Sonesson, 2019).

Hasta aquí las teorías generales sobre la traducción intersemiótica, cuya relevancia y pertinencia ha crecido en las últimas dos décadas. A continuación, abordaremos las propuestas operativas específicas que han surgido en años recientes para el análisis de obras de ficción que transitan entre la escritura y el audiovisual.

\section{ESTUDIOS DE TRADUCCIÓN INTERSEMIÓTICA, ALGUNAS PROPUESTAS}

El problema al que se enfrentan quienes pretenden aplicar la teoría al análisis de obras o traducciones específicas no es menor, se trata de establecer las equivalencias de los lenguajes, partiendo de un conocimiento profundo de sus características y posibilidades. Debido a su abundancia y relevancia sociocultural, no es sorprendente que muchos de los estudios de traducción intersemiótica se concentren en la transmutación de textos literarios en películas (Cid Jurado, 2017) ${ }^{8}$. Los análisis cinematográficos se han ocupado desde sus inicios de este fenómeno, conocido inicial y generalmente como adaptación cinematográfica. No obstante, la noción de adaptación ha sido cuestionada por establecer una relación desigual entre ambos artes, como Robert Stam señala, al hablar de adaptación se parte muchas veces del desprecio de la literatura hacia el cine y la superioridad artística de la misma (2009).

\footnotetext{
${ }^{8}$ No obstante, el estudio de la transposición de la imagen (generalmente pintura) al texto escrito y a la inversa se ha apoyado principalmente en la écfrasis, práctica retórica clásica, que en ocasiones puede ser encontrada de forma velada (Eco, 2008). Un ejemplo de esto es el análisis que hace Kubilay Aktulum sobre Trabajo de Émile Zola, en la cual encuentra écfrasis de las obras impresionistas de sus contemporáneos (2017).
} 
Dentro de la teoría y análisis cinematográfico, la adaptación tiene su propio espacio, en diálogo con la literatura comparada, la narratología y la teoría de la traducción (Gimferrer, 1999; Sánchez Noriega, 2000; Hutcheon, 2007; Zavala, 2019). Para reemplazar el término "adaptación", también en este ámbito se han propuesto otros como transposición (Wolf, 2001) o trasvase (Sánchez Noriega, 2000). Las teorías lingüísticas y semióticas en torno a la narrativa son, junto con lo teoría de la traducción, pilares en los estudios del paso de una obra literaria a una cinematográfica o de una cinematográfica a una literaria. De nueva cuenta Genette, Greimas, Metz, y Barthes, son los referentes (Valles Calatrava, 2002). No es extraño, por tanto, que la mayoría de las propuestas expuestas a continuación se avoquen al análisis de obras de ficción.

Para el análisis concreto, Lauro Zavala ha propuesto un modelo que combina tanto la teoría de Jakobson como la glosemática de Hjelmslev. La glosemática narrativa propuestas por Zavala se presenta como una síntesis de teorías semióticas aplicadas al análisis de obras transmutadas. La aportación, además, está en la inclusión de los elementos de cada sistema semiótico, cuya esquematización permite realizar análisis más claros y dirigidos. Se trata de poder establecer equivalencias semánticas entre sistemas distintos, para lo cual es fundamental conocer los efectos retóricos y las funciones narrativas de cada elemento (2003). Para esto, Zavala inicialmente resume el lenguaje cinematográfico en cinco elementos característicos del cine convencional: la imagen, el sonido, el montaje o edición, la puesta en escena y la narración (2019). A estos elementos añade otros que son parte del esquema de la glosemática centrada en la narrativa: el género (forma del contenido), la ideología (sustancia del contenido), el intertexto, el inicio y el final (2009). Dentro de los elementos del lenguaje cinematográfico, el narrativo ocupa un lugar central en la teoría de Zavala (2016), y es por ello por lo que su aplicación más clara es para el análisis de obras de ficción.

Otra vía de estudio utilizado es el concepto de cronotopo, formulado por Mijaíl Bajtín en su Teoría y estética de la novela como, "la conexión esencial de relaciones temporales y espaciales asimiladas en la literatura" (1989: 237). Este cronotopo literario ha sido reinterpretado para insertarlo en el análisis cinematográfico, o inclusive para hablar de una dimensión cronotópica. Es el caso de los trabajos de Torop, quien se decanta por el concepto de cronotopo como punto de partida para el análisis de prosa y cine. Recupera el concepto de Bajtín para establecer tres tiempo-espacios posibles en una película; el cronotopo topográfico que conecta la diégesis con el mundo real, el cronotopo psicológico que transmite la evaluación o autoevaluación de los personajes y sucesos, y el cronotopo metafísico o mundo del autor (Torop, 2002; 2020). En un filme, señala Torop, pueden coincidir los tres o ser independientes e inclusive predominar uno sobre el resto, como lo ejemplifica en su análisis de Ana Karenina (2020). La dificultad de este modelo radica precisamente en la identificación de cada cronotopo y sus relaciones dentro de la obra, y, sin embargo, tal análisis involucra efectivamente el momento histórico de la obra y al autor/intérprete. 
Por su parte, la propuesta hecha por Alex Mendíbil se apropia del cronotopo de una forma distinta. Recuperando los postulados de Greimas sobre los anclajes cronotópicos y su ilusión de realidad, propone una tipología tripartita de cronotopos audiovisuales: documental, realista y expresionistas. El cronotopo documental sería aquel que no permite dudas sobre su existencia, el cronotopo realista permitiría la identificación sin tener que ser del todo real, y finalmente el cronotopo expresionista no pretende crear la ilusión de realidad, pero sí servir como signo (Mendíbil, 2015; Morales Zea, 2020). Este es un esquema más descriptivo y fácil de reconocer, que sin embargo mantiene al cronotopo como un elemento retórico más.

Otra propuesta, específica para los casos en los que la mutación es continuada, es la que Dusi (2020) ha realizado para el análisis de las reinterpretaciones transmedia en las que identifica un ecosistema medial, una semiosfera, de manera que cada transposición agrega información y hace más compleja la narración. Recupera la división hecha por Jason Mittel para diferenciar traducciones en las que la narración de llegada es centrípeta, es decir, que añaden elementos que no se incluían en el texto fuente pero que son coherentes y lógicos con la narración fuente (elementos visuales o detalles del pasado de los personajes); y aquellas de narración centrífuga, en donde la reinterpretación es más abierta y se permite actualizar el texto fuente a nivel narrativo. Este tipo de estudios es posible debido al crecimiento exponencial de traducciones intersemióticas en fechas recientes, las cuales no tienen reparo en recuperar elementos de obras anteriores - en su mayoría exitosas-, con fines publicitarios.

Cristian Palacios, por otro lado, recupera el análisis de Benveniste para establecer las diferencias entre los sistemas semióticos, que plateaba el principio de no redundancia entre sistemas, el cual indica que no existe sinonimia entre sistemas, esto es, no se puede decir lo mismo con un sistema diferente (Benveniste, 1999: 56). Abona así a la idea de que no es posible la fidelidad en los casos de transposición intersemiótica. Asimismo, Palacios emplea los conceptos de transformación de Claude Lévi-Strauss, y de supervivencia de Aby Warburg, pues considera que éstos explican mejor la transposición entre sistemas tales como el cine y la historieta (2018).

Por último, es pertinente resaltar la Teoría Sistémica Funcional de Michael Halliday, que ha sido aplicada al estudio de las notas periodísticas, es decir en textos de no ficción. Esta teoría propone considerar tres metafunciones presentes en toda traducción intersemiótica: el significado ideacional, que se basa en la experiencia y crea conexiones lógicas en el mundo; el significado interpersonal, que permite las relaciones sociales y crea una postura hacia el mundo; y el significado textual, para organizar los significados experimental, lógico e interpersonal dentro del mensaje (O’Halloran, 2016: 204). Kay O’Halloran señala que dicha teoría se complementa con el Análisis Multimodal del Discurso, que considera tres dimensiones clave: el campo (naturaleza de la actividad social); el tenor (la relación social en la que se emite); y el modo (la forma de representación ya sea hablada, escrita, visual etc.) (O’Halloran, 2016: 205-206). Todo 
con el objetivo de identificar los cambios de significado o los nuevos significados que tienen lugar a través de la traducción intersemiótica.

\section{CONCLUSIONES}

La traducción intersemiótica dio nombre a un fenómeno cada vez más omnipresente y diverso, el flujo de ideas entre sistemas semióticos. Se diferencia de la intertextualidad por su especificidad, puesto que mientras la primera se refiere a todo tipo de presencia de un texto en otro, la traducción intersemiótica ocurre como un cambio programado del lenguaje de un texto. No obstante, la traducción intersemiótica parece ser cada vez más claramente inadecuada para referir el fenómeno. Otros términos como transposición (Dusi y Sonesson) podrían ser mejor opción o, quizá el cambio de adjetivo a sustantivo en intersemiósis (Torop), con lo cual se lograría mantener el vínculo directo con Jakobson. Lo cierto es que a la fecha la comunidad no ha alcanzado un acuerdo al respecto, por lo cual se prefiere mantener el término más antiguo como referente general, pese a las críticas.

Uno de los grandes avances en torno la traducción intersemiótica es la superación del prejuicio hacia el texto de llegada. En el caso de los estudios cinematográficos esto se deduce del concepto mismo de adaptación y la exigencia habitual de fidelidad. La teoría de la traducción y la teoría de la intertextualidad han evidenciado, sin embargo, que en la comunicación el intérprete y el contexto de llegada son incluso más importantes que cualquier intento de fidelidad, así como el hecho de que ninguna obra es completamente original. Por el contrario, las más recientes teorías platean la comunicación actual y su cultura como una red de referencias cruzadas, constante y cada vez más amplia. Además, el reconocimiento de la imposibilidad de encontrar equivalencias entre sistemas permite entender la transposición como un proceso que implica siempre cambios o sustituciones.

Las distintas propuestas para el estudio de textos intersemióticos muestran que la narrativa y la recepción de la obra son los ejes sobre los cuales se puede desarrollar el análisis de obras específicas. En todo caso, la diversidad de géneros y medios tanto de los textos de llegada como de los textos fuente, puede hacer más pertinente uno u otro tipo de análisis. Una muestra de esto es la división entre obras de ficción y no ficción, una diferenciación que sería interesante estudiar para el caso de las obras históricas. De igual forma, la existencia de redes de transposición amplias, como es el caso de las derivadas de obras clásicas o de éxitos de la pantalla grande, posibilitan estudios semióticos de más amplio alcance, al constituirse como semiosferas autónomas y autorrefenciales. Finalmente, la narrativa — mítica o no-, se ha erigido como eje para cualquier posible estudio de traducción intersemiótica, al servir como trasfondo que permite comparar por encima de las adecuaciones y mutaciones producto de la negociación. 


\section{REFERENCIAS BIBLIOGRÁFICAS}

AKtulum, K. (2017). ·What Is Intersemiotics? A Short Definition and Some Examples". International Journal of Social Science and Humanity 7.1, 33-36. Disponible en línea: http://ijssh.org/vol7/791-HS0013.pdf [30/04/2020].

BAjtín, M. (1989). Teoría y estética de la novela. Trabajos de investigación. España: Taurus.

BARThES, R. (2004). S/Z, N. Rosa (trad.). Buenos Aires: Siglo XXI. (2011). Mitologías, H. Schmucler (trad.). México: Siglo XXI.

Benveniste, E. (1999). Problemas de lingüistica general 2. J. Almela (trad.). México: Siglo XXI.

BRYlla, C. (2004). "How are Films Endings shaped by the socio-cultural context. Part 1". Image \& Narrative. Online Magazine of the Visual Narrative 8. Disponible en línea:

https://www.researchgate.net/publication/ 272677238_How_are_film_endings_shaped_by_their_sociohistorical_context_II [04/03/2020].

CÁCERES, M. (2003). "Lotman en español: difusión y recepción crítica". Entretextos. Revista Electrónica Semestral de Estudios Semióticos de la Cultura 2, 89-109. Disponible en línea: https://israelleon.files.wordpress.com/2010/02/ entretextos2.pdf [30/11/2020].

CAlabrese, O. (2000). "Lo strano caso dell'equivalenza imperfetta (modeste osservazioni sulla traduzione intersemiotica)". VS 85-87, 101-120.

Chatman, S. (1978). Story and Discourse. Narrative Structure and Fiction and Film. Estados Unidos: Cornell University Press.

Cid Jurado, A. (2017). "El mecanismo de la violencia. El signo en la traducción intersemiótica". deSignis 27 [Número monográfico sobre Cine y Literatura. Interferencias e Intersecciones], S. Schlickers, J. Türschmann y M. Satarain (coords.), 181-192. Disponible en línea: http://www.designisfels.net/ revista/27/designis-i27p181-192.pdf [12/12/2020].

Dusi, N. (2015). "Intersemiotic translation: Theories, problems, analysis". Semiotica 206, 181-205. Disponible en línea: https://www.researchgate.net/publication/ 282801476_Intersemiotic_translation_Theories_problems_analysis [30/04/2020].

(2020). "The Name of the Rose: Novel, Film, TV Series between Intermediality and Transmediality". Punctum. International Journal of Semiotic 6.1, 69-83. Disponible en línea: https://punctum.gr/2020-0004/ [12/11/2020].

ECO, U. (1984). Apocalípticos e integrados. Barcelona: Lumen. (2001). Experience in Translation, A. Mc Ewan (trad.). Buffalo: University of Toronto Press.

(2004). Mouse or Rat? Translation as Negotiation. London: Weidenfeld \& Nicholson. 
(2008). Decir casi lo mismo. Experiencias de traducción. H. Lozano Miralles (trad.). México: Lumen.

Genette, G. (1989a). Palimpsestos. La literatura en segundo grado, C. Fernández Prieto (trad.). Madrid: Taurus.

(1989b). Figuras III, C. Manzano (trad.). Barcelona: Lumen.

Gimferrer, P. (1999). Cine y literatura. Barcelona: Seix Barral.

GREIMAS, A. (1973). En torno al sentido: ensayos semióticos. Madrid: Fragua.

(1987 [1966]). Semántica estructural. Investigación metodológica. Madrid: Gredos.

Greimas, A. Y J. CourTÉs (1982 [1979]). Semiótica. Diccionario razonado de la teoría del lenguaje. Madrid: Gredos.

HJelmslev, L. (1971 [1943]). Prolegómenos a una teoría del lenguaje, J. L. Díaz de Liaño (a cargo de la versión española). Madrid: Gredos.

HutCHEON, L. (2007). A Theory of Adaptation. New York: Routledge.

JAKOBSON, R. (1959). "On linguistic aspects of translation". En On Translation, R. Brower (ed.), 232-239. Cambridge, MA: Harvard University Press. (1963). Essais de linguistique générale. Les fondations du langage. Paris: Les Éditons de Minuit.

(1976). “¿Decadencia en el cine?”. En Contribuciones al análisis semiológico del film, J. Urrutia (ed.), 173-182. Valencia: Fernando Torres.

(1988). Obras selectas I, J. L. Melena, G. Costas y V. Diéz (a cargo de la versión española). Madrid: Gredos.

Kristeva, J. (1997). "Bajtin, la palabra, el diálogo y la novela". En Intertextualité.

Francia en el origen de un término y el desarrollo de un concepto, D. Navarro (selección y traducción), 1-24. La Habana: UNAC / Casa de las Américas / Embajada de Francia en Cuba.

LOTMAN, I. (1998). La semiosfera II. La semiótica de la cultura, del texto, de la conducta y del espacio, D. Navarro (trad.). Madrid: Frónesis Cátedra / Universitat de València.

MendíBIL, A. (2015). "La ciudad y otros cronotopos en el cine de Jesús Franco". Actas Ícono 14. IV Congreso Internacional de Ciudades Creativas. Disponible en línea: https://www.academia.edu/22187384/LA_CIUDAD_Y_OTROS_CRONOTOPOS _EN_EL_CINE_DE_JESS_FRANCO[12/03/2020].

Metz, C. (1970). "La gran sintagmática del film narrativo". En Análisis estructural del relato, R. Barthes et al. / B. Dorriots (trad.), 147-153. Buenos Aires: Tiempo Contemporáneo.

(1973). Lenguaje y cine. Barcelona: Planeta.

(2002). Ensayos sobre la significación en el cine (1964-1968), 2 vols. Barcelona: Paidós Ibérica.

Morales ZeA, M. (2020). "Juárez y Maximiliano. Contrastes en la narración en el cine y la literatura". Fuentes humanísticas 32.61, s. p. Disponible en línea: 
http://fuenteshumanisticas.azc.uam.mx/index.php/rfh/article/view/978 [23/06/2021].

O'Halloran, K., S. TAN \& Wignell, P. (2016) "Intersemiotic Translations as Resemiotisation: A Multimodal Perspective”. Signata. Annals of Semiotic 7, 199229. Disponible en línea: https://journals.openedition.org/signata/1223 $[08 / 12 / 2020]$.

PALACIOS, C. (2018). "Transformaciones y supervivencias. Notas sobre el problema de la transposición intersemiótica". Signo y Seña 33, 124-142.

PeIRCE, Ch. (1974). La ciencia de la semiótica. Buenos Aires: Ediciones Nueva Visión.

PUYAL, A. (2011). "El pensamiento cinematográfico de Roman Jakobson". ARBOR Ciencia, pensamiento y cultura 187.748, 411-420. Disponible en línea: http://arbor.revistas.csic.es/index.php/arbor/article/view/1312 [24/05/2021].

SÁnCHEZ NoriegA, J. (2000). De la literatura al cine. Teoría y análisis de la adaptación. Barcelona: Paidós.

SonESSON, G. (2018-2019). "La traducción como doble acto de comunicación. Entre semiótica cognoscitiva y semiótica de la cultura. Parte I. De la comunicación a la traducción”. En Interpretatio. Revista de hermenéutica 3.2, 159-187. Disponible en línea: https://revistas-filologicas.unam.mx/interpretatio/index.php/in/article/ view/105 [10/11/2020].

(2019). "La traducción como doble acto de comunicación. Entre semiótica cognoscitiva y semiótica de la cultura. Parte II. De la traducción a la transposición". En Interpretatio. Revista de hermenéutica 4.1, 91-106. Disponible en línea: https://revistas-filologicas.unam.mx/interpretatio/index.php/in/article/ view/134/302[10/11/2020]

Stam, R. (2009). Teoría y práctica de la adaptación. México: Universidad Nacional Autónoma de México / Sepancine Asociación Mexicana de Teoría y Análisis Cinematográfico.

Torop, P. (1995). Totalny Perevod. Tartu: Universidad de Tartu.

(2002). "Intersemiosis y traducción intersemiótica". Cuicuilco. Nueva época 9.25.

Disponible en línea: https://www.redalyc.org/articulo.oa?id=35102502 [28/04/2020].

(2004). "Locations in Intersemiotic Space". En Place and Location. Studies in Environmental Aesthetics and Semiotics, V. Sarapik, E. Näripea \& K. Tüür (eds.), 59-68. Tallinn: Estonian Academy of Arts. Disponible en línea: https://www.academia.edu/23712006/Torop_Locations_in_Intersemiotic_Space [28/11/2020].

(2006). "La semiosfera y/como el objeto de investigación de la semiótica de la cultura”. Entretextos. Revista Electrónica Semestral de Estudios Semióticos de la Cultura 7. Disponible en línea: https://www.academia.edu/3830815/Torop [23/09/2020]. 
(2020). "The Chronotopical Aspect of Translatability in Intersemiotic Space". Punctum. International Journal of Semiotic 6.1, 265-284. Disponible en línea: https://punctum.gr/2020-0013 [9/12/2020].

Valles Calatrava, J. (2002). Diccionario de teoría de la narrativa. Salobreña (Granada): Alhulia.

VINELLI, E. (2009). “Traducción intersemiótica: revisión del debate de Bologna”. En VII Congreso Internacional Orbis Tertius de Teoría y Crítica Literaria, 18, 19 y 20 de mayo de 2009, La Plata. En Memoria Académica. Disponible en línea: http://www.memoria.fahce.unlp.edu.ar/trab_eventos/ev.3630/ev.3630.pdf [24/03/2020].

Wolf, S. (2001). Cine / Literatura. Ritos de pasaje. Buenos Aires: Paidós.

Zavala, L. (2003). Elementos del discurso cinematográfico. México: Universidad Autónoma Metropolitana / Unidad Xochimilco.

(2009). "La traducción intersemiótica en el cine de ficción”. Ciencia Ergo Sum 16.1, 47-54.

(2010). “Cine y literatura. Puentes, analogías y extrapolaciones". Razón y Palabra

71. Disponible en línea: http://www.razonypalabra.org.mx/N/N71/TEXTOS/ ZAVALA\%20REVISADO.pdf [13/08/2020]

(2016). "Las fórmulas narrativas en cine y literatura: Una propuesta paradigmática". Comunicación y Medios 34, 70-81.

(2019). "Una glosemática narrativa para la traducción intersemiótica". En Estudios actuales de literatura comparada: teorías de la literatura y diálogos interdisciplinarios, R. Cubillo y R. Campos (eds.), 42-62. San José: Vicerrectoría de Investigación / Universidad de Costa Rica.

(c) $\$($ This work is licensed under a Creative Commons AttributionBY NC ND NonCommercial-NoDerivatives 4.0 International (CC BY-NC-ND).

Fecha de recepción: 15/01/2021

Fecha de aceptación: 25/06/2021 